\title{
Laboreal
}

Volume $2 \mathrm{~N}^{\circ} 1$ | 2006

Varia

\section{Entre o local e o global : processos de regulação para a preservação da saúde no trabalho}

Entre lo local y lo global: proceso de regulación para la preservación de la salud en el trabajo

Entre le local et le global : processus de régulation pour la préservation de la santé au travail

Between the local and the global : regulation process to health at work preservation

\section{Carla Barros-Duarte}

\section{(2) OpenEdition}

\section{Journals}

Edição electrónica

URL: http://journals.openedition.org/laboreal/13761

DOI: 10.4000/laboreal. 13761

ISSN: 1646-5237

\section{Editora}

Universidade do Porto

\section{Refêrencia eletrónica}

Carla Barros-Duarte, «Entre o local e o global : processos de regulação para a preservação da saúde no trabalho », Laboreal [Online], Volume $2 N^{0} 1$ | 2006, posto online no dia 01 julho 2006, consultado o 24 setembro 2020. URL : http://journals.openedition.org/laboreal/13761 ; DOI : https://doi.org/ 10.4000/laboreal.13761

Este documento foi criado de forma automática no dia 24 setembro 2020.

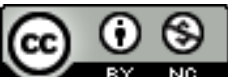

Laboreal está licenciado com uma Licença Creative Commons - Atribuição-NãoComercial 4.0 Internacional. 


\section{Entre o local e o global : processos de regulação para a preservação da saúde no trabalho}

Entre lo local y lo global : proceso de regulación para la preservación de la salud en el trabajo

Entre le local et le global : processus de régulation pour la préservation de la santé au travail

Between the local and the global : regulation process to health at work preservation

\section{Carla Barros-Duarte}

\section{REFERÊNCIA}

Barros-Duarte, C. (2004). Entre o local e o global : processos de regulação para a preservação da saúde no trabalho. Tese de Doutoramento. Faculdade de Psicologia e de Ciências da Educação da Universidade do Porto, Porto.

\section{Introdução}

1 O ponto de partida deste trabalho foi a constatação que, apesar de estudos científicos desenvolvidos no domínio da saúde no trabalho terem vindo a demonstrar a influência do trabalho e das condições de trabalho na saúde e no bem-estar dos trabalhadores, assiste-se ainda a poucas mudanças na concretização de uma política global e integradora da dimensão do trabalho na abordagem da saúde. De facto, a pouca visibilidade social dos dados estatísticos é muitas vezes reforçada pela ausência de vontade dos próprios trabalhadores em falar do seu trabalho e das suas condições de 
trabalho, optando, assim, por uma discrição social Canguilhem (2002), e, consequentemente, para a ocultação dos efeitos do trabalho na saúde.

2 Na realidade, as relações entre a saúde e o trabalho revestemse de uma grande complexidade, "não são nem unívocas nem instantâneas" (Gollac \& Volkoff, 2000, p. 23) estabelecem-se relações múltiplas e recíprocas que, ultrapassando os tradicionais diagnósticos de doença, se traduzem, também, num conjunto de fenómenos e estados não patológicos mas reveladores de sofrimento (Marquié, 1999) e que continuam, ainda, pouco visíveis. Foi o confronto com este aparente paradoxo que incentivou o processo de investigação desenvolvido, tendo como principal objectivo compreender a ausência de visibilidade dos efeitos do trabalho na saúde recorrendo nomeadamente, a partir do quadro teórico da psicologia do trabalho e da ergonomia da actividade, ao estudo dos processos de regulação assumidos pelos trabalhadores.

3 Na verdade, neste trabalho, tendo como contexto de investigação o sector da Indústria Têxtil e do Vestuário (ITV), foi realizado um conjunto de estudos situados em três níveis de análise que, entre o global e o local, permitiram dar outra visibilidade à questão da saúde no trabalho :

- A nível sectorial foi desenvolvido um estudo do tipo epidemiológico a partir do Inquérito SIT

- Inquérito Saúde, Idade e Trabalho;

- A nível da empresa foi realizado um estudo de caso numa das empresas participantes no Inquérito SIT onde se desenvolveu uma investigação-acção junto de um colectivo de trabalhadores ;

4 A nível local foi desenvolvido um estudo no seio da comunidade, fortemente dominada pela ITV, onde se localiza a empresa estudada : aqui, procurou-se analisar o papel que os diferentes grupos de protagonistas na área da saúde e da saúde pública têm no registo e diagnóstico dos efeitos do trabalho no estado de saúde.

\section{Saúde e trabalho : relações e evoluções}

5 A investigação desenvolvida teve subjacente os principais resultados dos estudos dos processos de envelhecimento no e pelo trabalho (Teiger, 1989; Marquié, Paumès, \& Volkoff, 1995 ; Derriennic, Touranchet \& Volkoff, 1996; Volkoff, Molinié \& Jolivet, 2000 ; Cassou et al., 2001) procurando realçar a complexidade da análise das relações entre o trabalho e a saúde, designadamente ao nível do impacto das condições de trabalho. De facto, a diversidade e a variabilidade que caracterizam as relações entre saúde e trabalho envolvem a compreensão de um conjunto de factores que interagem mutuamente e a diferentes níveis nos vários momentos da vida do indivíduo solicitando, assim, uma abordagem global e multifacetada.

6 Sabe-se que, na realidade, as consequências do trabalho no estado psico-fisiológico não tem, normalmente, uma expressão imediata e linear e, embora acompanhem todo o ciclo de vida do indivíduo, manifestam-se frequentemente de forma diferida e singular estabelecendo-se relações diversas e recíprocas com o trabalho (Gollac \& Volkoff, 2000), que não são vivenciadas da mesma maneira por todos os trabalhadores

7 O Inquérito SIT - Saúde, Idade e Trabalho - cuja lógica de base se enquadra nos estudos de tipo epidemiológico, foi construído a partir dos contributos dos inquéritos ESTEV $(1990,1995)$ e VISAT $(1996,2001)$ que, fora de Portugal, já demonstraram as suas potencialidades. 
O objectivo principal deste tipo de instrumento é o de compreender como e em que medida as condições de trabalho actuais e passadas influenciam, favorável ou desfavoravelmente, a qualidade do processo de envelhecimento e a evolução do estado de saúde.

Nesta perspectiva, o Inquérito SIT procurou reconstruir o percurso e a história profissional do trabalhador, assim como a evolução das condições da sua saúde. De facto, o Inquérito SIT, procurou ultrapassar os objectivos dos primeiros modelos de epidemiologia profissional, baseados no estudo da relação directa e unívoca entre uma causa e uma patologia específica, para modelos de epidemiologia mais recentes em que se procura integrar outros factores nomeadamente as características profissionais, as condições de trabalho, os factores extra-profissionais e as condições de vida, abarcando igualmente as queixas e os problemas ditos "infra-patológicos" nas suas relações com o trabalho.

10 A análise das relações menos visíveis entre a saúde e o trabalho abre também uma nova perspectiva, uma nova forma de olhar a saúde no trabalho, direccionada para uma abordagem centrada no trabalhador: a integração da perspectiva do trabalhador, traduzida nas percepções, nas queixas e nos sentimentos acerca da sua saúde, possibilita uma abordagem mais global e mais dinâmica.

11 A análise dos resultados do Inquérito SIT contribuiu para a identificação dos principais riscos profissionais e dos problemas de saúde mais frequentes na ITV, sublinhando os efeitos não só das características físicas do trabalho mas, também, do conteúdo e da organização do trabalho, realçando a importância dos pequenos problemas de saúde associados ao trabalho.

12 Contudo, este estudo confirmou a necessidade de uma análise complementar, mais específica da problemática estudada centrada na compreensão das estratégias e dos processos de regulação desenvolvidos pelos trabalhadores nas situações concretas de trabalho o que levou ao desenvolvimento de uma investigação-acção junto de um colectivo de trabalhadores.

\section{A preservação e construção da saúde no trabalho : processos de regulação}

13 Partindo dos princípios delineados por Faverge (1966), o estudo dos processos de regulação da saúde no trabalho suscita uma reflexão que realça a especificidade e a singularidade do comportamento do homem no trabalho nomeadamente na procura nem sempre fácil - de um equilíbrio entre o que é exigido pelo cumprimento das normas de produção e o que exige a preservação da saúde.

Nesta perspectiva, a intervenção apela a uma abordagem mais compreensiva do que explicativa (Volkoff, 2002): privilegia escutar, entender e compreender a saúde (Honoré, 2002) abrindo, assim, caminho a um novo olhar, mais centrado no vivenciado do trabalhador e apoiado numa dimensão mais existencialista da saúde (Canguilhem, 2002).

15 De facto, se o estudo dos processos de regulação da saúde no trabalho envolve, assim, a compreensão dos modos de agir, de pensar e de sentir dos trabalhadores (Lacomblez, 2004), também realça o debate de valores que atravessa a gestão que cada um faz da sua vida de trabalho (Schwartz, 2000) : dar um significado e um sentido ao que acontece no 
trabalho traduz a dimensão de cariz existencial que invade permanentemente o mundo de trabalho e que reflecte frequentemente o que acontece também no mundo fora do trabalho (Curie, 2002 ; Davezies, 2002).

o estudo desenvolvido concretizou-se numa acção de formação realizada numa empresa da ITV junto de um colectivo de doze trabalhadores e teve como principal objectivo promover uma reflexão sobre as consequências das condições de trabalho na saúde e no bem-estar. A metodologia utilizada caracterizou-se pela combinação de entrevistas individuais e de entrevistas colectivas que, progressivamente, favoreceram a partilha, a emergência e a confrontação de diferentes representações sobre as relações entre a saúde e o trabalho.

Os resultados evidenciaram mudanças ao nível do discurso dos trabalhadores, nomeadamente nos modos de pensar/reflectir as relações entre a saúde e o trabalho, revelando uma progressiva sistematização colectiva das condições de trabalho evidenciando, assim, uma outra explicitação na tomada de consciência das relações entre saúde e trabalho.

A análise das estratégias de regulação desenvolvidas pelos trabalhadores realçou ainda uma grande variedade de modos de regulação, adoptados por cada um.

De facto, os critérios referidos na gestão dos constrangimentos da actividade de trabalho mostram que, apesar de se traduzirem sobretudo na alteração e ajustamento dos modos operatórios - regulações operatórias (Faverge, 1966) - a partir das características antropométricas e morfológicas de cada um, são também desenvolvidas formas mais peculiares de preservar a sua saúde - regulações catacréticas (De Keyser, 1972) o trabalhador altera a finalidade de um determinado instrumento, acção ou mesmo pensamento, de modo a adaptar-se à realidade concreta de trabalho preservando a sua saúde e o seu bem-estar. As estratégias de regulação da saúde revelam, assim, uma maneira bem própria de regular o seu trabalho de modo a diminuir os constrangimentos, recuperar o tempo e alcançar um equilíbrio possível, revelando, também, a interferência de valores pessoais decorrentes de uma experiência que não se limita ao mundo laboral.

20 A confrontação e o debate colectivo centrado no real do trabalho favoreceram a possibilidade de se dizer o que até aí era vivido no silêncio, de explicitar, de desenvolver, de melhor definir, de recorrer às experiências da vida fora do trabalho e de comparar modos de pensar/sentir, interpretações, estratégias e soluções.

21 Ao longo do processo de intervenção o discurso dos trabalhadores foi evoluindo : se nas primeiras etapas, a gestão da saúde no trabalho se caracterizava por preocupações relacionadas, sobretudo, com a gestão do uso de si, gradualmente, emergiram um conjunto de valores que Yves Schwartz integra no registo dos "valores sem dimensão " distintos dos valores de mercado - que correspondem aos valores da política, da deliberação democrática, do direito social, do direito ao trabalho (Schwartz, 2000). E a situação colectiva de partilha com os pares e os investigadores parece ter tido um papel decisivo para a formação de uma rede de apoio integradora e de reflexão.

Todavia, esta intervenção, pelos impasses com que o projecto do seu alargamento se confrontou ao nível da empresa, acabou por reorientar os seus objectivos num campo de intervenção da saúde pública. Procurou-se privilegiar, então, a interface com os centros de saúde da comunidade local, realçando mais concretamente o papel dos 
médicos de família - responsáveis, também, pela evolução do estado de saúde destes trabalhadores.

\section{A organização da saúde : intervir na construção de interfaces}

23 A partir da experiência conduzida por Marc Andeol e Gilbert Igonet na região das "Bouches du Rhône" (Association pour la Prise en Charge des Maladies Eliminables, 2005 ; Le quotidien du Médecin, 2006), impulsionada por Ivar Oddone (Oddone, 1999), procurou-se analisar a interface entre a realidade previamente estudada e os centros de saúde da comunidade local, mais concretamente o papel dos médicos de família.

24 A análise de um conjunto de entrevistas individuais realizadas a 18 médicos dos centros de saúde revelou que, nas preocupações com os cuidados globais de saúde e de saúde pública, persiste, ainda, uma insuficiente integração da influência determinante que o trabalho pode ter na saúde e no bem-estar numa região em que é elevada a frequência de doenças profissionais típicas dos trabalhadores da ITV, como a surdez profissional e a bissinose $(54 \%$ e $28 \%$, respectivamente, das doenças profissionais reconhecidas naquela comunidade local).

De facto, a maior parte dos médicos afirma desconhecer o tipo de actividade de trabalho desenvolvida na ITV assim como as condições de trabalho mais típicas nas empresas do sector, apesar de a maioria dos seus utentes ( $80 \%)$ trabalhar ou já ter trabalhado neste sector.

26 A aparente incoerência entre as doenças profissionais reconhecidas e o conteúdo do discurso dos médicos de família constitui um factor singular em termos de intervenção: por um lado, "a grande maioria dos médicos não possui nenhum conhecimento do trabalho industrial (em sentido lato, ou seja, do trabalho na sociedade industrial) e não existe nenhum incentivo profissional ou financeiro" para tal (Thébaud-Mony, 1991, p. 71), por outro lado, o isolamento profissional no qual acabam por assumir as suas funções é flagrante assim como a ausência de qualquer apoio ao nível dos conhecimentos e informações sobre a realidade de trabalho. E, consequentemente, a prevenção desenvolvida afasta-se, cada vez mais, do local de trabalho, privilegiando o controlo dos factores de risco subjacentes aos comportamentos individuais e a promoção de "estilos de vida saudáveis » (Ministério da Saúde, 2004), dependentes, aparentemente, da boa vontade dos trabalhadores.

\section{Perspectivas e desafios}

As questões relativas à saúde no trabalho apelam a uma intervenção a vários níveis que ultrapassa, certamente, o nível da empresa e envolve diferentes actores que, ao nível local, podem interferir na preservação e construção da saúde e do bem-estar.

Contudo, as acções existentes mostram-se ainda insuficientes colocando em questão os actuais mecanismos de regulação institucionais que, muito dependentes do poder central, acabam por levar ao isolamento os organismos locais, dificultando a análise das necessidades mais específicas da comunidade. 
29 A implementação de redes e estruturas de apoio que favoreçam a construção de capacidades individuais e colectivas de debate e de acção (Davezies, 2002) no domínio da saúde necessita, pois, de uma outra forma de perspectivar a organização da saúde ao nível local que passa, sobretudo, pelo desenvolvimento de processos concretos de coordenação entre os diferentes grupos de protagonistas que podem interferir na preservação e construção de um bem comum que é a saúde.

Os resultados desta investigação evidenciaram a necessidade do reforço e/ou da criação de estruturas e redes de apoio, susceptíveis de assumir melhor a função reguladora de uma política da saúde que deixaria de esquecer que a maior parte dos cidadãos exerce uma actividade profissional.

\section{BIBLIOGRAFIA}

Association pour la Prise en Charge des Maladies Eliminables (2005). Rapport d'Activité 2003-2006. Évaluation interne de l'utilisation des Fonds d'Aide à la Qualité des Soins de Ville (FAQAV). Bouchesdu-Rhône : APCME.

Canguilhem, G. (2002). Ecrits sur la médecine. Paris : Éditions du Seuil. Cassou, B., Buisset, C., Brugère, D., Davezies, P., Derriennic, F., Desplanques, G., Laville, A., Marquié, J-C., Touranchet, A., \& Volkoff, S. (2001). Travail, Santé, Vieillissement : relations et évolutions. Toulouse : Éditions Octarès.

Curie, J. (2002). Dis-moi, Docteur, c'est grave ? Manuscrito não publicado.

Davezies, P. (2002). Bilan et défis. Prévention-Sécurité, 61, 30-38.

De Keyser, V. (1972). Fiabilité et expérience. In CECA, Études de Physiologie et de Psychologie du Travail, no 7, Fiabilité et Sécurité Eléments pour une ergonomie des systèmes en milieu industriel (pp. 77-137). Luxembourg : Diffusion des Connaissances - Commission des Communautés Européennes.

Derriennic, F., Touranchet, A. \& Volkoff, S. (1996). Age, travail, santé. Paris : Les Editions INSERM.

Faverge, J.M. (1966). L'analyse du travail en terme de régulation. In : J.M. Faverge, M. Olivier, J. Delahaut, P. Stephaneck \& J.C. Falmagne. (Eds.), L'ergonomie des processus industriels (pp. 33-60). Bruxelles : Editions de l'Institut de Sociologie, Université de Bruxelles.

Gollac, M. \& Volkoff, S. (2000). Les conditions de travail. Paris : Editions La Découverte.

Honoré, B. (2002). A Saúde em Projecto. (I. d’Espiney, Trad.). Loures : Lusociência.

Lacomblez, M. (2004, Janeiro) De Faverge à Vergnaud : entre variabilité et invariants dans le développement de l'activité. Communication présentée au colloque international ARDECO : Les processus de conceptualisation en débat : hommage à Gérard Vergnaud. Paris, France.

Le quotidien du Médecin (2006). Le quotidien du Médecin [version électronique]. Retiré le 7 février 2006, http://www.quotimed.com/journal/index.cfm?

fuseaction=viewarticle\&DartIdx $=22113243 \mathrm{k}$.. 
Marquié, J-C. (1999). Quelques composantes psychiques et cognitives de la relation âge, travail, santé. Colloque Santé, Travail, Vieillissement : Relations et Évolutions. Paris : CREAPT.

Marquié, J-C., Paumès, D. \& Volkoff, S. (1995). Le travail au fil de l'âge. Toulouse : Éditions Octarès.

Ministério da Saúde (2004). Programa nacional de intervenção integrada sobre determinantes da saúde relacionados com os estilos de vida [version électronique]. Retiré le 3 février 2005, de http://www.dgsaude.pt.

Oddone, I. (1999). Psicologia dell'organizzazione della salute. Psicología della Salute, Fascicolo 1. Schwartz, Y. (2000). Le paradigme ergologique ou un métier de philosophe. Toulouse : Octarès.

Teiger, C. (1989). Le vieillissement différentiel par et dans le travail : un vieux problème dans un contexte récent. Le Travail Humain, 52, 1, 21-56.

Thébaud-Mony, A. (1991). La reconnaissance des maladies professionnelles : acteurs et logiques sociales. Paris : La Documentation Française.

Volkoff, S. (2002). Des comptes à rendre : usages des analyses quantitatives en santé au travail pour l'ergonomie. Noisy-le-Grand: Centre d'Etudes de l'Emploi.

Volkoff, S., Molinié, A-F., \& Jolivet, A. (2000). Efficaces à tout âge ? Vieillissement démographique et activités de travail. Paris : Dossier du Centre d'Études de l’Emploi no 16.

\section{AUTOR}

\section{CARLA BARROS-DUARTE}

Universidade Fernando Pessoa Praça 9 de Abril, nº 349, 4249-004 Porto

cbarros@ufp.pt 